\title{
EFFECT OF THE AIR TO WATER RATIO ON THE PERFORMANCE OF INTERNAL MIXING TWO-FLUID ATOMISER
}

\author{
Piotr Krawczyk*, Krzysztof Badyda, Szczepan Młynarz \\ Warsaw University of Technology, Institute of Heat Engineering, 21/25 Nowowiejska Str., 00-665 \\ Warsaw, Poland
}

\begin{abstract}
One of the important parameters describing pneumatic liquid atomisation is the air to liquid mass ratio $(A L R)$. Along with the atomiser design and properties of the liquid it has extremely important influence on parameters of atomised liquid such as: mean droplet diameter, jet range and angle. Knowledge about real characteristics of an atomiser in this respect is necessary to correctly choose its operating parameters in industrial applications.

The paper presents results of experimental research of two-fluid atomisers with internal mixing built according to custom design. Investigated atomizers were designed for spraying a urea aqueous solution inside the power boiler combustion chamber. They are an important element of SNCR (selective non-catalytic reduction) installation which is used to reduce nitrogen oxides in a flue gas boiler. Obtained results were used by authors in further research, among others to determine the boundary conditions in the SNCR installation modeling.

The research included determining mean droplet diameter as a function of ALR. It has been based on the immersion liquid method and on the use of specialised instrumentation for determining distribution of droplet diameters in a spray - Spraytec by Malvern. Results obtained with both methods were later compared. The measurements were performed at a laboratory stand located at the Institute of Heat Engineering, Warsaw University of Technology. The stand enables extensive investigation of the water atomisation process.
\end{abstract}

Keywords: liquid atomisation, internal mixing two-fluid atomisers, mean diameter, SNCR

\section{INTRODUCTION}

Liquid atomisation is a process very significant to many areas of engineering, including power engineering e.g. in flue gas denitrification technology for power boilers (Krawczyk and Badyda 2014; Wrzesińska et al., 2015), chemical industry, automotive industry, air-conditioning, agriculture and medicine (Broniarz-Press et al., 2015; Sosnowski and Żołądkowicz 2011).

Atomisers may be used as standalone systems or as parts of larger assemblies, such as a boiler burner, agricultural sprinkler, a component of a fire-suppression system etc. Depending on the function, atomiser design and operating parameters may considerably vary.

One of the essential features of any atomiser which characterise its operation is spray quality defined through parameters such as mean diameter of a droplet in the spray or atomisation spectrum (Ashgritz, 2011; Orzechowski and Prywer, 1994). Knowledge of these properties is necessary to correctly choose an atomiser design. It also enables running calculations concerning droplet movements or heat and mass transfer between droplets and surrounding fluid. Nonetheless, despite atomisers being commonly 
used in various industrial applications, published sources do not propose methods for comprehensive and unambiguous description of the spray mechanism or theoretic determination of relations between operating parameters on one hand, and e.g. droplet diameter on the other for most atomiser designs. Sizes of droplets obtained by liquid atomisation depend partially on uncontrollable parameters, e.g. interference, vibrations, liquid turbulence (Broniarz-Press et al., 2009; Liu et al., 2006; Orzechowski and Prywer 2008; Ramesh et al., 1984). Thus the atomisation process yields droplets of different diameters and the process has a statistical character.

There is an extensive literature on two-fluid atomisers. In the publication (Lefebvre, 1992) the principal factors governing the mean drop sizes produced by two-fluid atomisers were indicated. According to this paper the principal factors governing the fineness of atomisation are: air velocity, air/liquid ratio, and surface tension.

The authors of the publication (Ferreira et. al., 2009) have carried out the research on two-fluid atomisers with an internal mixing chamber for heavy fuel oils. They also indicate ALR as one of the important parameters describing pneumatic liquid atomisation.

In the publication (Nguyen and Rhodes, 1998) semi-empirical correlations for volume median drop diameter with atomiser geometry and operating conditions for two-fluid type atomiser (dedicated for producing fine drops) was presented.

Most available information concerning characteristics of atomiser operations is a result of experimental research. This paper is an attempt to fit into this trend by presenting results of experimental tests carried out on custom-designed internal mixing two-fluid atomisers (Krawczyk and Badyda, 2015). Presented results focus on mutual relation between the amount of air supplied to the atomiser and mean diameter of droplets formed by atomisation. Investigated atomisers were designed for spraying a urea aqueous solution inside the power boiler combustion chamber during SNCR system operation. No information concerning parameters of atomisers dedicated for this type of application has been found in scientific literature.

The Selective Non-Catalytic Reduction (SNCR) technology for NOx emission abatement from industrial boilers involves injecting a reducing agent directly into a high temperature zone of the combustion chamber. Reaction between the $\mathrm{NH} 2$ radical and nitrogen oxides contained in the flue gas yields nitrogen, carbon dioxide and water (Thanh et al., 2008). Radicals are generated through thermal decomposition of reducing agents e.g. urea. Reagent injection parameters (such as the diameter of a droplet) should be changed along with the change of boiler operating conditions. Therefore, it is extremely important to know the relationships between atomiser design as well as their operating parameters and the atomisation quality.

\section{EXPERIMENTAL RESEARCH}

\subsection{Investigated atomisers}

In two-fluid atomisers the flows may be arranged in different ways. One of the main methods for classification of such devise may be based on the dominating phase (gas or liquid).

The main components of the tested atomisers were:

- mixing chamber - volume in which gas-liquid contact occurs,

- exhaust nozzle - which leads the gas-liquid mixture outside the atomiser,

- duct connecting the mixing chamber to the exhaust nozzle. 


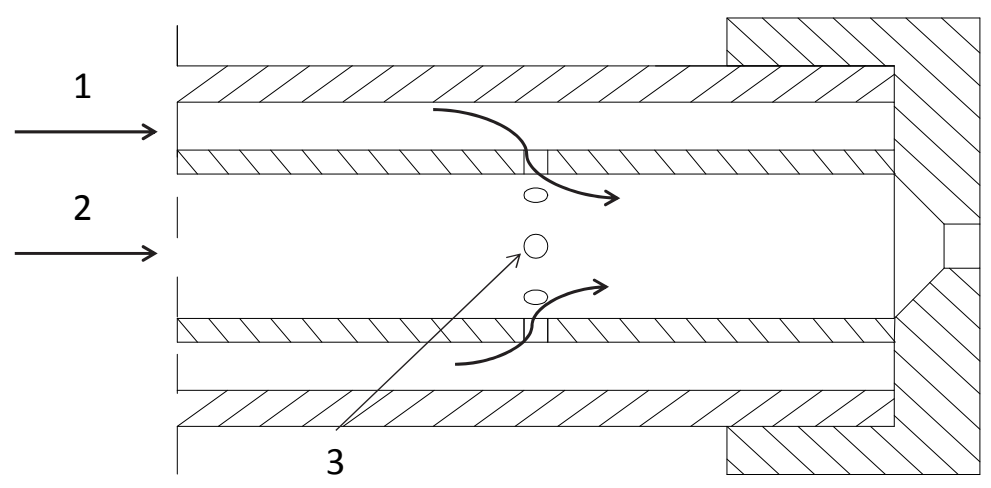

Fig. 1. Schematic drawing of the investigated atomiser: 1 - liquid flow, 2 - gas flow, 3 - orifices through which liquid is injected into gas in the mixing chamber

In the investigated type of atomiser, gas flows through the main duct in the mixing chamber, while the liquid is introduced perpendicularly to the gas flow direction. Such a design is schematically shown in Fig. 1.

In this type of atomiser, liquid jet is atomised within the mixing chamber. Then increasing velocity of gas-liquid mixture within the converging section of the nozzle leads to the droplets being further broken into smaller pieces. General information about the internal mixing two-fluid atomisers can be found in (Ashgritz, 2011; Chin and Lefebvre, 1995; Orzechowski and Prywer, 1994).

The investigated atomiser had a modular structure, which enabled replacing individual components. The tests involved analysis of five different design variants. The difference between them was diameter of the outlet nozzle, which had following values in individual test series:

- $d_{1}=1.5 \mathrm{~mm}$,

- $d_{2}=2 \mathrm{~mm}$,

- $d_{3}=3 \mathrm{~mm}$,

- $d_{4}=3.5 \mathrm{~mm}$,

- $d_{5}=4 \mathrm{~mm}$.

Remaining geometric parameters of the atomiser, such as diameter of the mixing chamber and length of the duct connecting mixing chamber to the exhaust nozzle were not changed. Using several different nozzle diameters allowed to extend the range of $A L R$ values which could be investigated. The test stand was provided with a source of compressed air with a maximum supply pressure of 6 bar. Atomised liquid was water supplied at ambient temperature $\left(20^{\circ} \mathrm{C}\right)$. Investigation covered flows from 20 to 40 litres per hour.

\subsection{Test stand}

The measurements were performed at a laboratory stand located at the Institute of Heat Engineering, Warsaw University of Technology. The stand enables extensive investigation of the water atomisation process. Its main components include:

- water and compressed air supply systems, along with relevant instrumentation and control components,

- mount for the investigated atomiser,

- injection chamber with dimensions ensuring free water distribution.

Equipment of the stand permits determining and controlling both flows and pressures of media supplied to the atomiser. 
The supply-instrumentation section consists of:

- rotodynamic water pump with a lift height up to $90 \mathrm{~m}$,

- buffer tank for atomised water,

- compressor with a buffer tank (pressure in tank 7.5 bar),

- compressed air pressure reduction station,

- two rotameters with different measured ranges for water $(1-10 \mathrm{l} / \mathrm{h}$ and $10-100 \mathrm{l} / \mathrm{h})$,

- two rotameters with different measured ranges for air $\left(1.2-12 \mathrm{~m}^{3} / \mathrm{h}\right.$ and $\left.4-40 \mathrm{~m}^{3} / \mathrm{h}\right)$,

- one bimetallic thermometer for air and one for water (measurement range $-20-60{ }^{\circ} \mathrm{C}$ ),

- four control valves (two for air and two for water),

- two electronic pressure gauges (one for air and one for water),

- isolation valves,

- control valve on pump bypass.

Figure 2 presents a schematic of the test stand configuration and instrumentation. Water was delivered with Warsaw water supply network (pure, potable water).

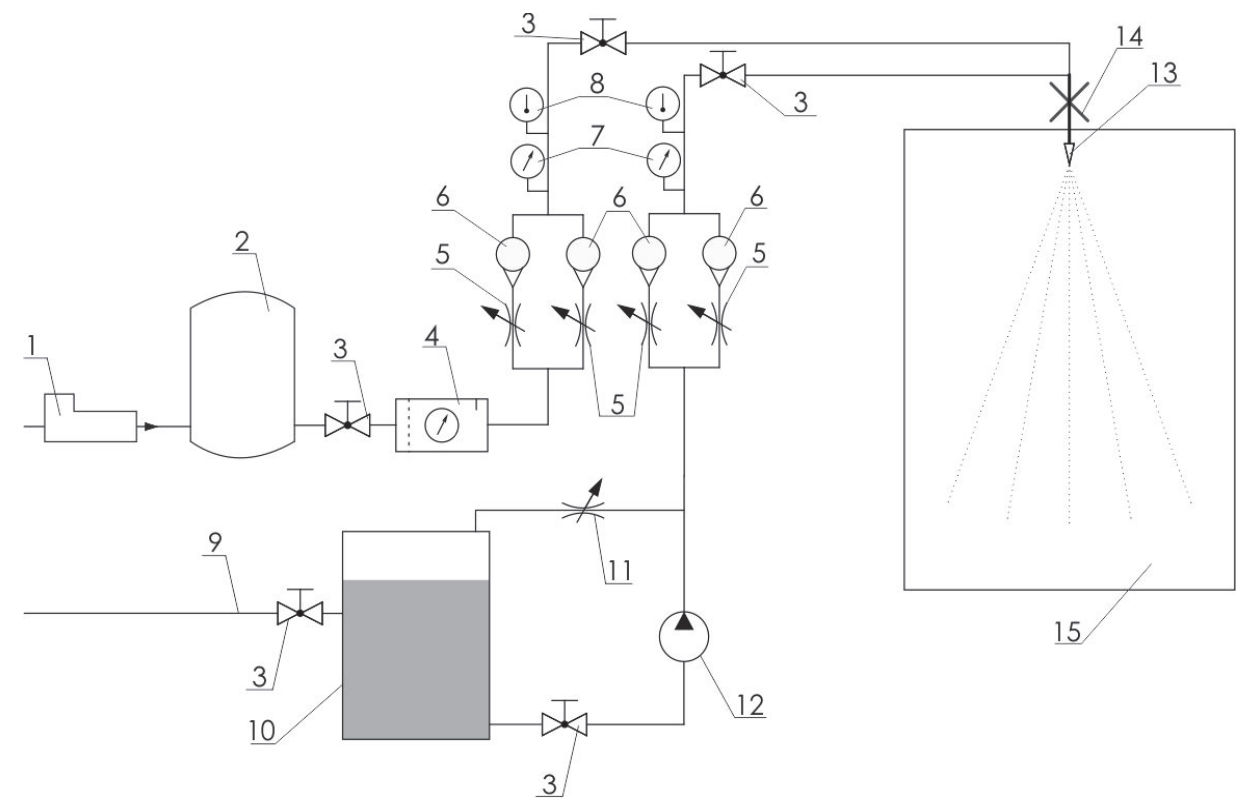

Fig. 2. Schematic of the test stand configuration and instrumentation;

1- compressor, 2 - air buffer tank, 3- shut-off valve, 4- compressed air pressure reduction station; 5- flow control valve, 6- rotameter, 7- manometer, 8 - thermometer, 9- water service line, 10- water storage tank, 11- by-pass flow control valve, 12- pump, 13-atomiser, 14- mount for the investigated atomiser, 15 - injection chamber

\subsection{Measurement methodology}

The goal of the research was to determine the influence of atomiser's operating parameters (air to liquid ratio, $A L R$ ) on atomisation quality expressed by the mean droplet diameter. $A L R$ was defined as:

$$
A L R=\frac{\dot{m}_{A}}{\dot{m}_{W}}
$$

The mean droplet diameter is a conventional value which characterises a set of homogenous droplets used as an equivalent of a real set (atomisation spectrum).

Depending on the calculation method, mean droplet diameter may be determined as an arithmetic mean, area mean or volumetric mean. The parameter most frequently adopted for analysing heat and mass transfer processes is $d_{32}$ diameter (Sauter mean diameter). It describes a diameter of droplets 
within a homogenous equivalent set with the same total volume and area of all droplets as the real set (Barreras et al., 2006).

$$
d_{32}=S M D=\frac{\sum d^{3} \Delta N}{\sum d^{2} \Delta N}
$$

The Sauter mean diameter was used in our analysis.

In order to achieve the aim of the research, a series of measurements was taken for each of the tested design variants. During each series:

- water flow was changed - values of $0.02,0.03$ and $0.04 \mathrm{~m}^{3} / \mathrm{h}$ were used,

- air flow was changed in such a way that the overpressure in the atomiser's mixing chamber for each liquid flow would take consecutive values from 1.5 to 5 bar, with resolution of 1 ,

- droplet sizes in the spray were measured with two method: by immersion liquid method or with Spraytec analyser.

Then the results of measurement of mean droplet diameter were assigned to relevant $A L R$ values.

\subsubsection{Measurement of droplet size by catching in immersion liquid}

The method of droplet catching by immersion liquid involves depositing droplets on a plate or vessel coated with a thin layer of immersion liquid. Such a liquid should be chemically inert, transparent and have lower density than that of the atomised liquid (Broniarz-Press et al., 2013). It also may not mix with the atomised liquid, it must have low evaporation pressure and low surface tension. The tests described here used LEDA silicone oil.

The procedure for taking measurements was as follows:

- a layer of silicone oil was applied to a microscopic slide,

- slide with the coat of oil was mounted on an extension arm,

- arm with the slide was introduced into relevant spray area, with the slide's back turned towards the spray,

- the slide was quickly rotated with its face towards the incident spray and then back to original position,

- after being cleaned from water accumulated below, the slide was placed under microscope and $2-6$ photographs with representative view of drops from the sample were made.

Samples of droplets were collected within the core of the spray, $1 \mathrm{~m}$ from the nozzle exhaust.

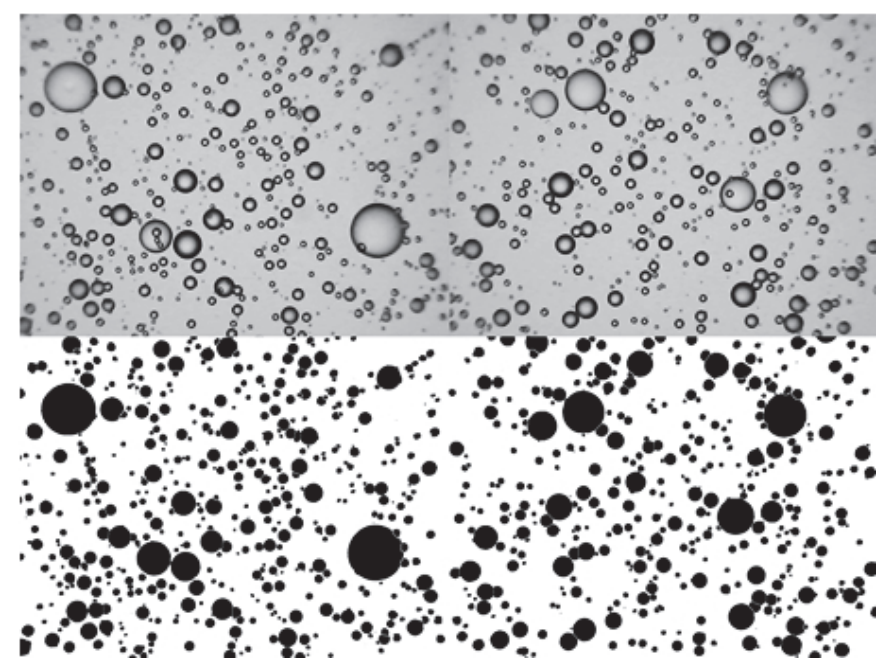

Fig. 3. Exemplary droplet photographs - images from the microscope and after processing with ImageJ software 
Droplet photographs made during measurements were subsequently analysed with ImageJ picture processing software. ImageJ is one of multiple graphic suites which enables to determine enable determining distribution of droplet diameters. The programme enables automatic calculation of surface areas occupied by individual droplets visible in the photo. In order to permit this operation, a photograph must be prepared in a proper way: the image must be converted into 8-bit and binary format; also proper settings like circularity of analysed objects and minimum droplet size need to be set. Figure 3 presents exemplary photographs of droplets made using a microscope and processed with ImageJ software.

Measurements made by catching droplets on a layer of immersion liquid were very labour-intensive, both at the stage of sampling and analysing photographs, and statistical calculations.

\subsubsection{Droplet size measurements with Spraytec analyser}

Except for the immersion liquid method, also Malvern's Spraytec device was used to measure the droplet diameters. This analyser performs measurements based on laser diffraction method. Spraytec automatically measures diameters of droplets within aerosol or spray with high density. It permits real time measurements of droplet size spectrum. Distribution of droplet sizes is generated immediately and shows changes of spray properties over time (Hoffmann et al., 2013). Files with a full set of measured data are recorded in computer memory. This is a considerably more convenient and faster method of measuring parameters than the method presented before. This method also needs to be seen as more accurate, averaging results across entire section of spray, instead of only measuring a small area as in case of using immersion liquid. The photograph below (Fig. 4) presents the Spraytec device during measurements at the test stand. Just like in case of the immersion liquid method, measurements were made at a distance of $1 \mathrm{~m}$ from the nozzle outlet. The measurements were performed in a continuous mode. The frequency of droplet sampling was $1 \mathrm{~s}$ and the averaging time of measured size distributions was $60 \mathrm{~s}$. During measurements, 300mm lens system, covering a $0.1-900$ micron dynamic range was used. According to the manufacturer, Spraytec measurement accuracy is better than $+/-1 \%$ on the Dv50.

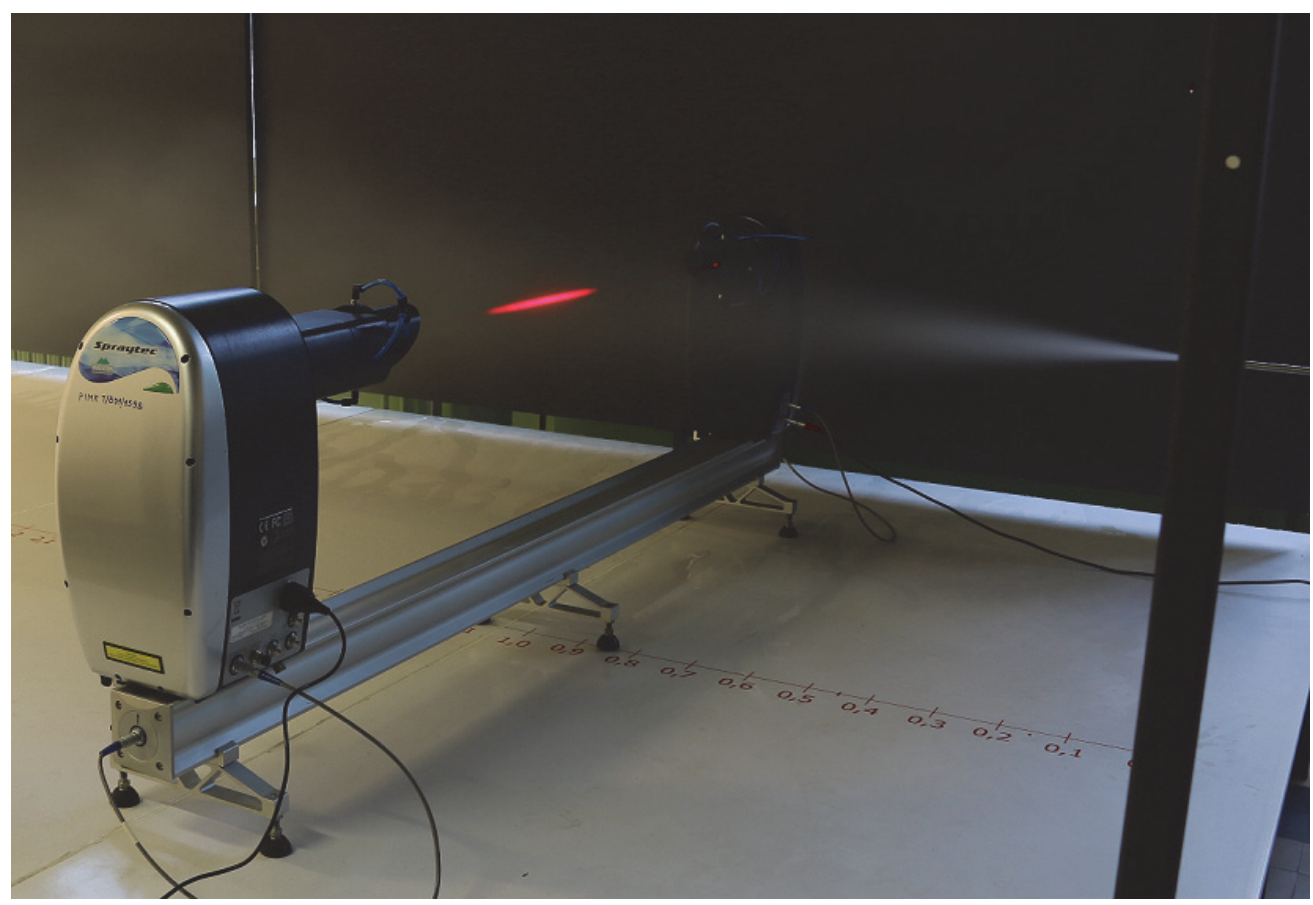

Fig. 4. Spraytec device during measurements at the test stand 


\section{MEASUREMENT RESULTS}

Each of investigated atomiser configurations permitted a different range of compressed air flow, therefore also different range of $A L R$ values. The range of possible gas flows is strictly dependent on the exhaust nozzle diameter. Detailed information on recorded extreme values of air flow and $A L R$ is shown in Table 1 below.

Table 1. Extreme values of air flow and $A L R$ obtained for individual investigated atomiser configurations

\begin{tabular}{|c|c|c|c|c|}
\hline Nozzle diameter & $\begin{array}{c}\text { Minimum tested } \\
\text { air flow }(\mathrm{kg} / \mathrm{s})\end{array}$ & $\begin{array}{c}\text { Maximum tested } \\
\text { air flow }(\mathrm{kg} / \mathrm{s})\end{array}$ & Minimum ALR & Maximum ALR \\
\hline $1.5 \mathrm{~mm}$ & 1.7 & 4.3 & 0.048 & 0.213 \\
\hline $2.0 \mathrm{~mm}$ & 2.09 & 9.39 & 0.052 & 0.47 \\
\hline $3.0 \mathrm{~mm}$ & 6.6 & 25 & 0.2 & 1.3 \\
\hline $3.5 \mathrm{~mm}$ & 10.1 & 30.8 & 0.3 & 1.5 \\
\hline $4.0 \mathrm{~mm}$ & 13.3 & 32.1 & 0.3 & 1.6 \\
\hline
\end{tabular}

All the results showing dependency between the mean droplet diameter and flow of compressed air supplied to the atomiser obtained during the tests for all analysed configurations are presented in charts below (Figs. 5 and 6). Also presented are results of measurements of mean droplet sizes obtained with both methods discussed above.

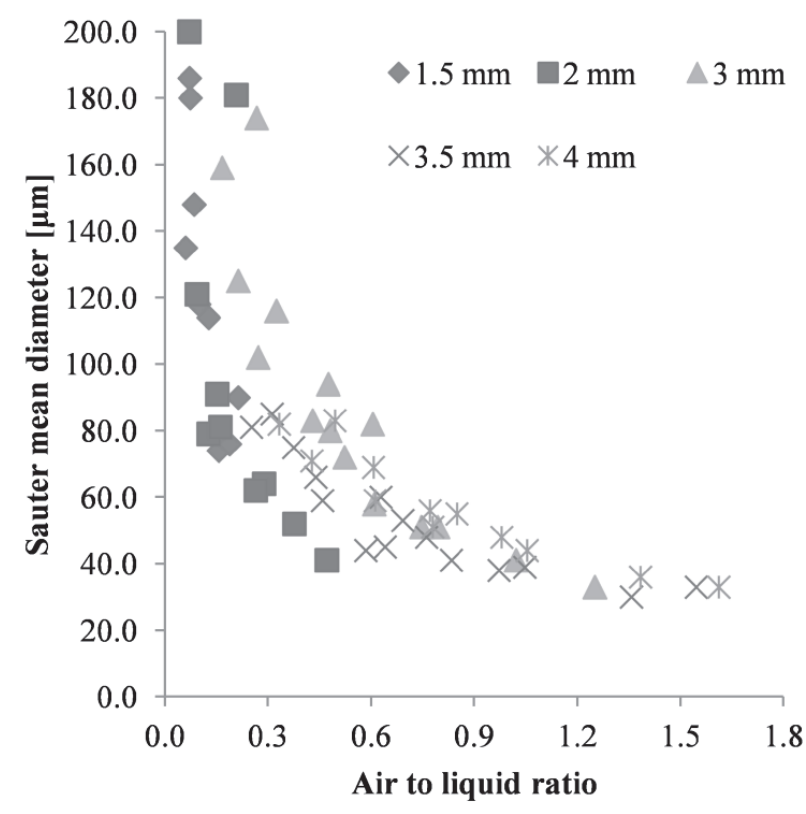

Fig. 5. Mean diameter of droplets of dispersed spray as a function of $A L R$. Results obtained with immersion liquid for different nozzle diameters

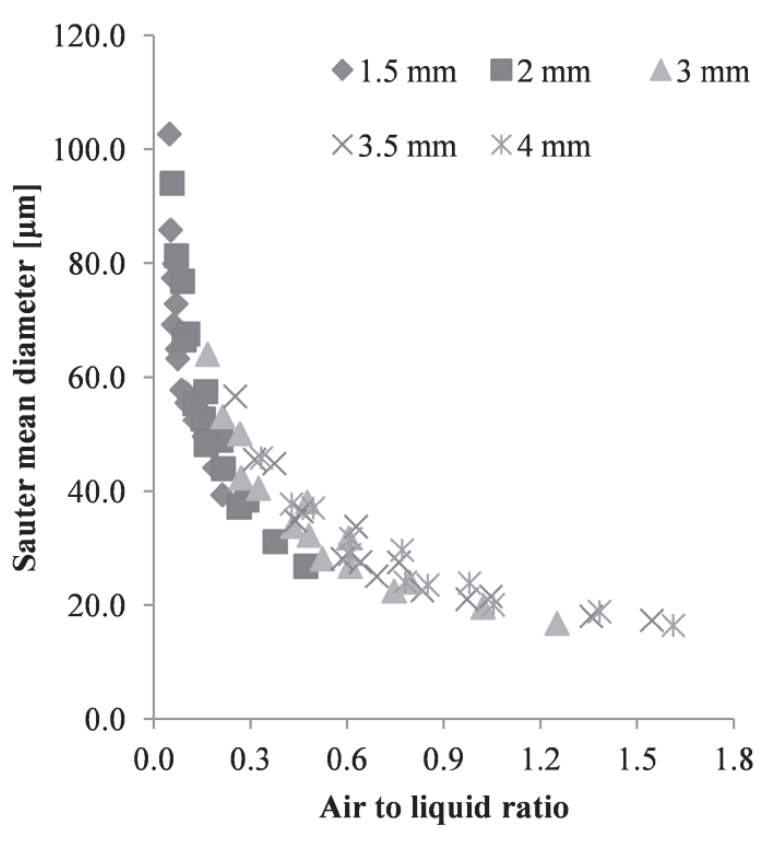

Fig. 6. Mean diameter of droplets of dispersed spray as a function of $A L R$. Results obtained with Spraytec analyser for different nozzle diameters

Analysis of the above diagrams reveals that:

- there is a correlation between the amount of compressed air supplied to the atomiser and the mean droplet diameter in the spray. It can be clearly seen that increase of $A L R$ value leads to decrease of the mean droplet size for all investigated atomiser configurations. This conclusion appears also in other works on this subject (Li et al., 2012; Watanawanyooa et al., 2011; Yudav 
and Kushari, 2011). For low $A L R$ values (up to some 0.4) the dependency between droplet size and $A L R$ is stronger (curves are steeper),

- mean droplet diameters measured with Spraytec device are considerably lower than those obtained by catching in immersion liquid (MCI). In authors' opinion the differences may result from:

- the fact that the measurement with immersion liquid was performed locally in the centre of the spray, while Spraytec measured diameters across the whole horizontal section of the spray,

- insufficient number of droplets (poor statistics) for measurement with immersion liquid,

- insufficient resolution of optical instruments (smallest droplets not visible),

- short observation depth (some droplet may be out of focus and cannot be recognized by the software),

- low sampling efficiency (small droplets can avoid inertial catching on the surface of immersion oil).

- results obtained with immersion liquid method have much weaker correlation with $A L R$ than those obtained with Spraytec (smaller scatter of measurement points),

- differences between mean droplet diameter values obtained with Spraytec and those obtained with MCI method are largest for low $A L R$ values and diminish as the air flow increases. However, it should be assessed that the differences between mean droplet diameter values obtained with both methods are very high in the whole analysed $A L R$ range. In addition, MCI method is extremely labour-intensive compared to Sprytec analyser. Therefore it seems that immersion method is inapplicable for realistic determination of SMD.

Analysis of the presented data leads to a conclusion that the nozzle diameter as a design parameter does not directly influence atomisation quality. It only influences it indirectly by restricting achievable $A L R$ values. Based on presented results it may be concluded that atomisers working with nozzles of different diameters, but at the same $A L R$ value will achieve the same $\mathrm{d}_{32}$ mean droplet diameter $(S M D)$.

In addition, exemplary information (obtained with Spraytec) about the size droplet distribution in dispersed spray for different $A L R$ values is shown in the following charts (Figs. 7 and 8).

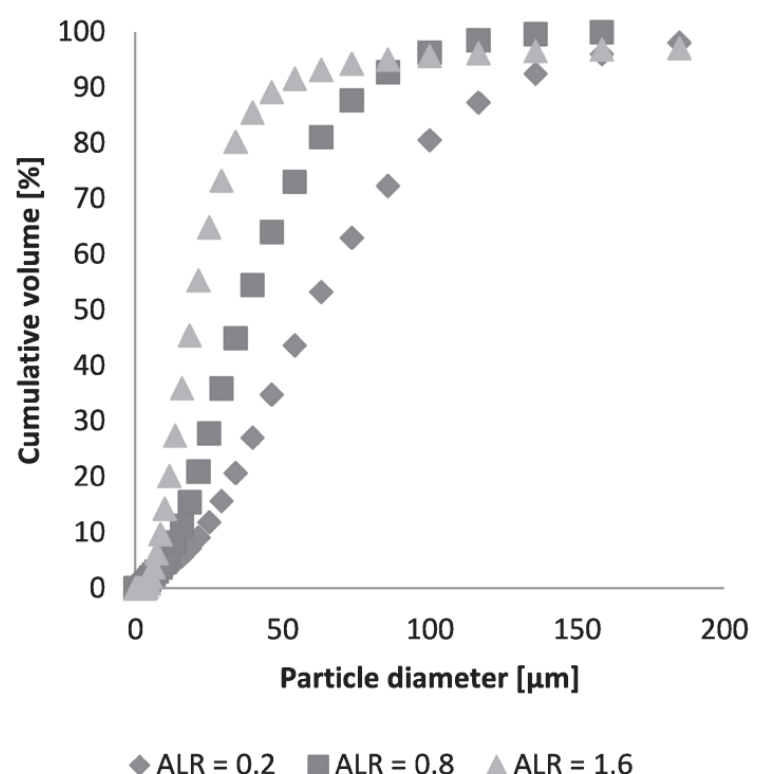

Fig. 7. Droplet size distribution (cumulative volume) in dispersed spray for different $A L R$ values. Results obtained with Spraytec analyser

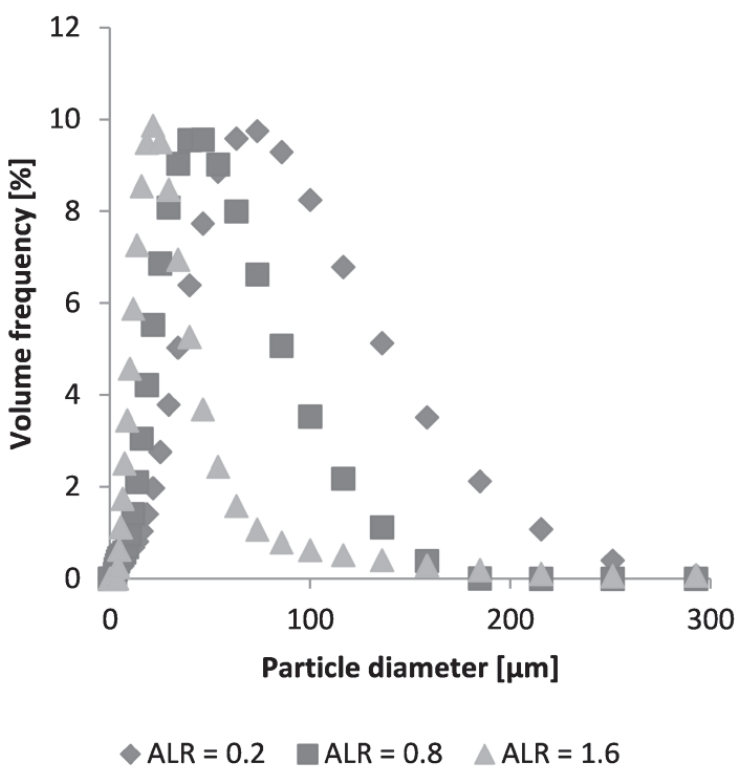

Fig. 8. Droplet size distribution (volume frequency) in dispersed spray for different $A L R$ values. Results obtained with Spraytec analyser 
According to the above data, higher $A L R$ value leads to:

- reduction of droplet diameters,

- reduction of a range of variation in the droplet diameters - span.

These observations are reflected in values of spray quality parameters $D v 10, D v 50$ and $D v 90$ (Fig. 9).

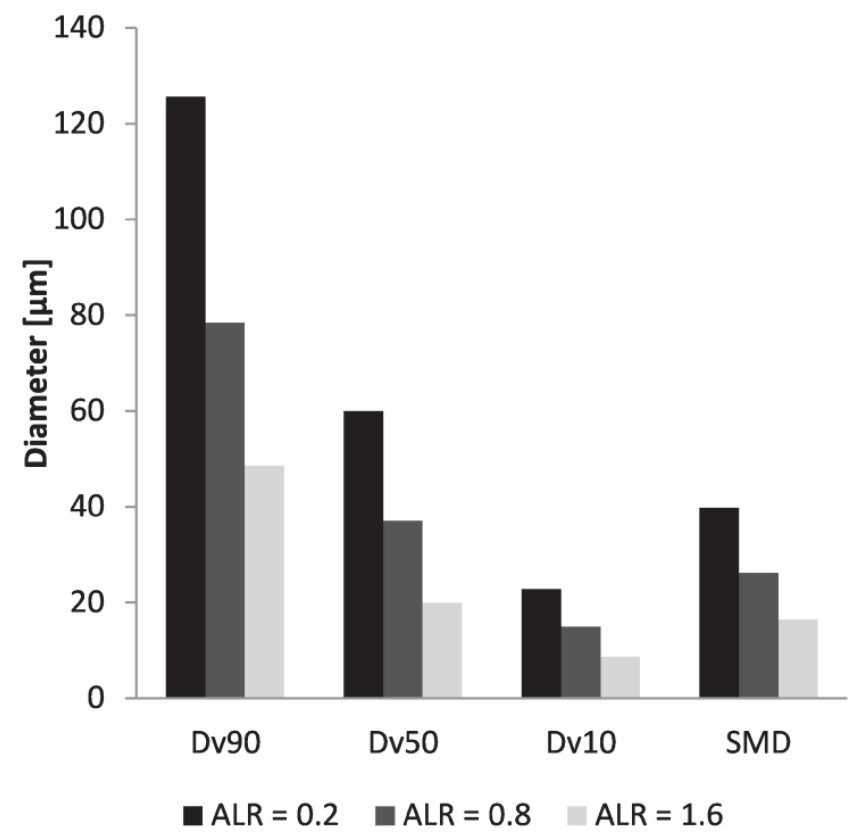

Fig. 9. Diameters of droplets of dispersed spray $(D v 10, D v 50, D v 90)$ for different $A L R$ values. Results obtained with Spraytec analyser.

\section{CONCLUSIONS}

Measurement results presented in the paper concern internal mixing two-fluid atomisers of our own design. Performed research focused on determining relation between the mean droplet diameter and air to liquid ratio $(A L R)$ for atomisers designed for spraying a urea aqueous solution inside the power boiler combustion chamber.

Obtained results demonstrated that there is a strong correlation between the amount of compressed air supplied to the atomiser and quality of liquid spray understood here as the $d_{32}$ mean droplet diameter. Increase of air flow leads to reduction of this diameter. It is especially pronounced for low ALR values, up to some 0.4 .

Out of the two droplet size measurement methods - with Spraytec analyser and by catching in immersion liquid - the former proved much more accurate (smaller scatter of measured points, measurement accuracy better than $+/-1 \%$ on the Dv50 ) and convenient. On the other hand the immersion liquid method is cheaper and may be applied in any conditions.

Diameter values measured with Spraytec analyser are smaller than those obtained with the alternative method. In the authors' opinion those differences may result from the fact that the immersion liquid measurement was taken locally in the centre of the spray, while Spraytec analyser measured droplet 
diameters across the entire horizontal section. Besides, in the immersion liquid method randomness plays a considerable role, both at the stage of sample collection and when taking representative photographs. Thus this method is by its very nature burdened with errors and in authors' opinion may only be used for preliminary quick estimation of droplet size. For any ultimate research, however, it needs to be seen as insufficient.

This research is supported by the POIG.01.03.01-14-035/12 project which is co-financed by the European Regional Development Fund under the Operational Programme Innovative Economy.

\section{SYMBOLS}

$\begin{array}{ll}A L R & \text { air to liquid ratio, } \mathrm{kg} / \mathrm{kg} \\ D & \text { diameter, } \mathrm{m} \\ D v 10 & \text { the diameter below which } 10 \% \text { of the liquid volume is atomised into smaller droplets } \\ D v 50 & \text { the diameter below which } 50 \% \text { of the liquid volume is atomised into smaller droplets } \\ D v 90 & \text { the diameter below which } 90 \% \text { of the liquid volume is atomised into smaller droplets } \\ \dot{m} & \text { mass flow rate, } \mathrm{kg} / \mathrm{s} \\ p & \text { pressure, } \mathrm{Pa}\end{array}$

\section{Subscripts}

A air

W water

\section{REFERENCES}

Ashgritz N., 2011. Handbook of atomization and sprays. Theory and applications. Springer. DOI: 10.1007/978-14419-7264-4.

Barreras F., Lozano A., Barroso J., Lincheta E., 2006. Experimental characterization of industrial twin-fluid atomizers. Atomization Sprays, 16, 127-145. DOI: 10.1615/AtomizSpr.v16.i2.10.

Broniarz-Press L., Ochowiak M., Markuszewska M., Włodarczak S., 2013. Wpływ lepkości cieczy na proces rozpylania w inhalatorach medycznych. Inż. Ap. Chem., 52, 4, 291-292.

Broniarz-Press L., Ochowiak M., Rozanski J., Woziwodzki S., 2009. The atomization of water-oil emulsions. Exp. Thermal Fluid Sci., 33, 955-962. DOI: 10.1016/j.expthermflusci.2009.04.002.

Broniarz-Press L., Sosnowski T.R., Matuszak M., Ochowiak M., Jabłczyńska K., 2015. The effect of shear and extensional viscosities on atomization of Newtonian and non-Newtonian fluids in ultrasonic inhaler. Int. J. Pharm., 485, 41-49. DOI: 10.1016/j.ijpharm.2015.02.065.

Ferreira G., García J. A., Barreras F., Lozano, A., Linchet E., 2009. Design optimization of twin-fluid atomizers with an internal mixing chamber for heavy fuel oils. Fuel Process. Technol., 90, 270-278. DOI: 10.1016/j.fuproc.2008.09.013.

Hoffmann W.C., Fritz B.K., Farooq M., Walker T. W., Czaczyk Z., Hornsby J., Bonds J.A.S, 2013. Evaluation of aerial spray technologies for adult mosquito control applications. J. Plant Prot. Res., 53. DOI: 10.2478/jppr2013-0034.

Krawczyk P., Badyda K., 2014. Numerical analysis of the impact of parameters of urea solution injection on reagent penetration inside the combustion chamber of a WR 25 boiler. Rynek Energii, 6, 115-139.

Krawczyk P., Badyda K., 2015. A design procedure for „liquid to air” type atomisers based on air and water mixture outflow velocity. Chem. Process Eng., 36, 355-363. DOI: 10.1515/cpe-2015-0025.

Lefebvre A. H., 1992. Twin-fluid atomization: Factors influencing mean drop size. Atomization Sprays, 2, 101-119. DOI: 10.1615/AtomizSpr.v2.i2.30 .

Li Z., Wu Y., Cai C., Zhang H., Gong Y., Takeno K., Hashiguchi K., Lu J., 2012. Mixing and atomization characteristics in an internal-mixing twin-fluid atomizer. Fuel, 97, 306-314. DOI: 10.1016/j.fuel.2012.03.006. 
Liu H., Li W., Gong X., Cao X., Xu J., Chen X., Wang Y.-F., Yu G.-S., Wang F.-Ch., Yu Z.-H., 2006. Effect of liquid jet diameter on performance of coaxial two-fluid airblast atomizers. Chem. Eng. Processing, 45, 240-245. DOI: 10.1016/j.cep.2005.08.003.

Nguyen D.A., Rhodes M.J., 1998. Producing fine drops of water by twin-fluid atomisation. Powder Technol., 99, 285-292. DOI:10.1016/S0032-5910(98)00125-9.

Orzechowski Z., Prywer J., 1994. Rozpylanie cieczy w urządzeniach energetycznych. Wydawnictwa NaukowoTechniczne, Warszawa (in Polish).

Orzechowski Z., Prywer J., 2008. Wytwarzanie i zastosowanie rozpylonej cieczy. Wydawnictwa NaukowoTechniczne, Warszawa (in Polish).

Ramesh N.R., Sridhara K., Natarajan R., 1984. Studies on the atomization and combustion performance of a twinfluid acoustic atomizer. Fuel, 64, 1677-1679. DOI: 10.1016/0016-2361(85)90393-X.

Sosnowski T.R., Żołądkowicz J., 2011. Charakterystyka procesu atomizacji cieczy w układach z wibrująca membraną (VM) stosowanych w wybranych inhalatorach medycznych. Inż. Aparat. Chem., 50, 5, $100-101$.

Thanh D. B., Nguyen, Young-Il L., Seong-Joon K., Won-Hyeon E., Kyung-Seun Y., 2008. Experiment and computational fluid dynamics (CFD) simulation of urea-based selective noncatalytic reduction (SNCR) in a pilot-scale flow reactor. Energy Fuels, 22, 3864-3876. DOI: 10.1021/ef8004652.

Watanawanyooa P., Mochidac H. H. H., Furukawad T., Nakamurae M., Chaitepf S., 2011. Experimental investigations on spray characteristics in twin-fluid atomizer. Procedia Eng., 24, 866 - 872. DOI: 10.1016/j.proeng.2011.12.416.

Wrzesińska B., Krzywda R., Wąsowski T., Krawczyk P, Badyda K., 2015. Technologia selektywnej niekatalitycznej redukcji tlenków azotu pod kątem zastosowania jej w kotłach dla energetyki przemysłowej i ciepłownictwa. Przem. Chem., 94, 608-613. DOI: 10.15199/62.2015.4.22.

Yudav N.P., Kushari A., 2011. Behaviour of spray in a twin-fluid atomizer, ASME 2011 Turbo Exp: Turbine conference and exposition, Volume 2: Combustion, Fuels and Emissions, Parts A and B. Vancouver, British Columbia, Canada, 396, Paper No. GT2011-46162, 979-986. DOI: 10.1115/GT2011-46162.

Received 06 November 2015

Received in revised form 29 July 2016

Accepted 01 September 2016 